\title{
Redox Polymers as Electrode-Active Materials for Batteries
}

\author{
Birgit Esser*a,b,c (D) \\ ${ }^{a}$ Institute for Organic Chemistry, University of Freiburg, \\ Freiburg, Germany \\ ${ }^{\mathrm{b}}$ Freiburg Materials Research Center, University of Freiburg, \\ Freiburg, Germany \\ cCluster of Excellence livMatS @ FIT - Freiburg Center for Interactive Materials and \\ Bioinspired Technologies, University of Freiburg, \\ Freiburg, Germany \\ besser@oc.uni-freiburg.de
}

Received: 13.09.2019

Accepted after revision: 24.10.2019

DOI: 10.1055/s-0039-3401016; Art ID: om-19-0010-rev License terms: 다 (i) $\fallingdotseq$ (여

(c) 2019. The Author(s). This is an open access article published by Thieme under the terms of the Creative Commons Attribution-NonDerivative-NonCommercial-License, permitting copying and reproduction so long as the original work is given appropriate credit. Contents may not be used for commercial purposes, or adapted, remixed, transformed or built upon. (https://creativecommons.org/licenses/by-nc-nd/4.0/)

Abstract Organic cathode materials are promising candidates for a new generation of 'green batteries', since they have low toxicity and can be produced from renewable resources or from petroleum. This review shows that organic redox polymers can show excellent battery performance regarding cycling stability and rate capability, and attractive specific capacities are accessible. Radical polymers and redox polymers based on heteroaromatics demonstrate superior rate capabilities and cycling stabilities at fast C-rates as well as high discharge potentials of 3-4 V versus $\mathrm{Li} \mathrm{Li}^{+}$, while quinone- or imidebased polymers deliver high specific capacities of up to $260 \mathrm{mAh} \mathrm{g}^{-1}$ with stable cycling at moderate C-rates and lower discharge potentials. This review article highlights the underlying design principles showcasing selected examples of well-performing redox polymers.

Key words organic batteries, redox polymers, cathode materials, fast charging, transition metal-free, high cycling stability

\section{Introduction}

The increasing demand for electrical energy, in particular for consumer electronics and electric vehicles, has raised the need for rechargeable batteries with high electrochemical performance and safety, and, at the same time, with small

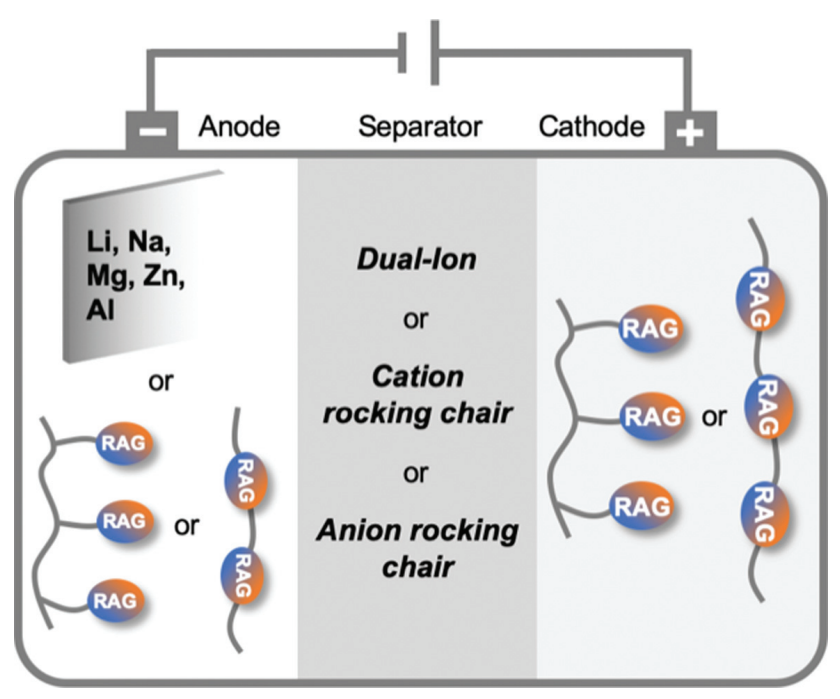

environmental footprint. Organic electrode materials are promising for such a next generation of 'green batteries'. The elements they are composed of $(\mathrm{C}, \mathrm{H}, \mathrm{N}, \mathrm{O}$, and $\mathrm{S})$ are abundant, and organic materials are often nontoxic and easier to process. Furthermore, their structures can be easily tailored to adjust their redox properties. In the past decade, a large variety of organic electrode materials have been developed, as summarized in several review articles in recent years. ${ }^{1-4}$ They can be used as cathode-active materials in metal-organic batteries or as both anode- and cathode-active materials in all-organic batteries. ${ }^{5}$ Different strategies have been identified to obtain high electrochemical performance of organic electrode materials in batteries. ${ }^{6,7}$ The most important parameters are the charge/discharge potential, specific capacity, rate capability, and cycling stability of the materials. ${ }^{2,6}$ The charge/discharge potential is determined by the structure of the redox-active groups, and the specific capacity by its molecular weight and the number of electrons partaking in the redox process. The rate capability depends on the rate of the electron- and ion-transfer processes in and out of the electrode. ${ }^{8}$ It is influenced by the electron-transfer rate constant of the redox-active group and the morphology of the composite electrode, usually consisting of a mixture of organic material, conductive carbon and binder. The cycling stability is often limited by either dissolution of the active material into the (usually liquid) battery electrolyte or by decomposition processes. One successful strategy to improve cycling stability and - in some cases - rate capability is to incorporate the redox-active molecular units into a polymeric structure. The resulting polymers are often insoluble in battery electrolytes but should remain swellable. Such socalled redox polymers have been defined as polymers 
Biographical Sketch

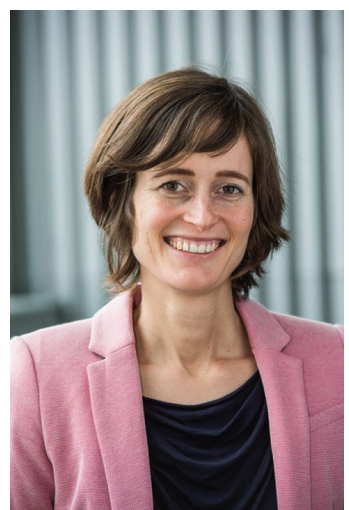

Birgit Esser is a professor for Molecular/Organic Functional Materials at the University of Freiburg since 2015. She obtained her Ph.D. in 2008 at the University of Heidel- berg. After postdoctoral studies at the Massachusetts Institute of Technology, she started her independent research group in 2012 at the University of Bonn. Her research focuses on organic electrode materials for batteries, small molecule semiconductors and hoop-shaped, conjugated $\pi$-systems. containing groups that can be reversibly reduced or oxidized. ${ }^{9}$ Two main design types A and B exist for such redox polymers: the redox-active groups can either be attached as side groups to an aliphatic or conjugated polymer backbone (type A) or they can be incorporated into the conjugated or nonconjugated polymer backbone (type B, Figure 1a).

Redox polymers are classified according to the redox reaction they preferentially undergo: in the case of an oxidation, the polymer is defined as a p-type, while in the case of a reduction, it is defined as an n-type polymer (Figure 1b). Bipolar materials, undergoing both types of reactions, also exist. As design guidelines for a battery application, the redox-active group should have a highly reversible redox chemistry at a potential attractive for an application as an anode- or cathode-active material, but at the same time be of low molecular mass. To obtain high specific capacities, the polymer backbone should impart the least amount of additional molecular weight. Using the molar mass of a polymer subunit $M$ (polymer subunit), the theoretical specific capacity of a redox polymer can be calculated according to the following equation (where $F$ is the Faraday constant and $n$ the number of electrons transferred per subunit):

$$
C_{\text {specific }}=\frac{\mathrm{n} \times F}{M(\text { polymer subunit })}=\frac{\mathrm{n} \times 26801}{M(\text { polymer subunit })}\left[\mathrm{mAh} \mathrm{g}^{-1}\right]
$$

To prepare a redox-polymer-based electrode, the polymer is usually mixed with a conductive carbon additive to obtain

(a)
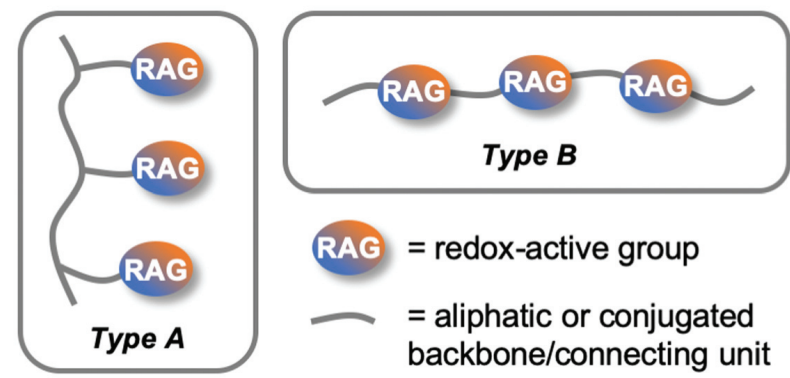

(b)

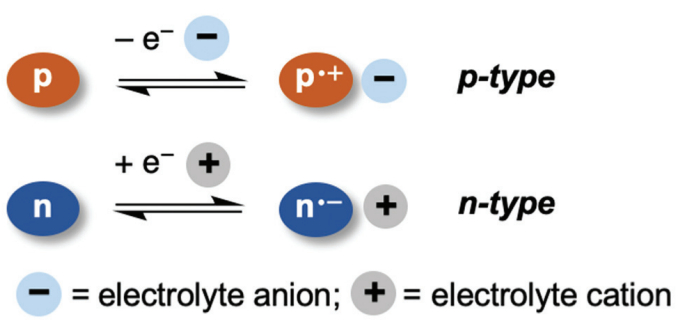

Figure 1 (a) Design types for redox-active polymers with the redox-active groups (RAGs) as pendant side units (type A) or incorporated into the main chain (type B); (b) redox reactions of p- or n-type organic compounds and charge balancing by electrolyte ions. 


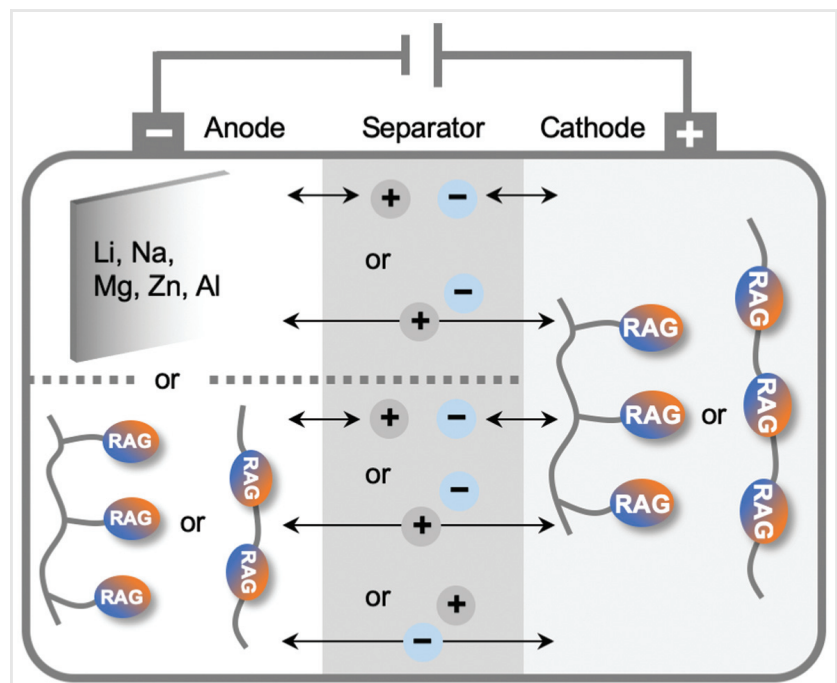

Figure 2 Schematic of a rechargeable battery with redox-active polymers as cathode-active materials combined with a metal anode or a redox-active polymer anode. Depending on whether the redox-active groups (RAGs) are p- or n-type, anions or cations from the electrolyte are required for charge balancing, respectively.

sufficient electronic conductivity. ${ }^{10}$ This adds to the inactive weight of the electrode, and the amount should therefore be held at a minimum. In most cases redox-active polymers are tested as cathode-active materials in half-cells against lithium as a counter electrode (Figure 2).,10,11 Sodi$u^{2,7,12,13}$ as well as multivalent metals, such as magnesium, zinc and aluminum, have also been used. ${ }^{14}$ If the polymer is of p-type, such metal-organic cells operate in a dual-ion mode, where both electrolyte cations and anions are required for charge balancing in the anode and cathode, respectively. ${ }^{15,16}$ With an n-type polymer, only metal cations are needed, resulting in a cation rocking-chair battery. For all-organic batteries, redox-active polymers serve as both anode- and cathode-active materials. ${ }^{5}$ Three configurations are possible: combining an n-type polymer as the anode with a p-type polymer on the cathode side leads to a dual-ion configuration. Using only n-type polymers, a cation rocking-chair battery results, while with p-type polymers as the anode and active materials as the cathode, the battery operates in an anion rocking-chair mode. The progress in all-organic batteries has recently been reviewed. ${ }^{5,17}$

\section{Redox Polymers as Electrode Materials}

The use of redox polymers as battery electrode materials has been reviewed on several occasions. ${ }^{10,18-22} \mathrm{~A}$ few selected examples will be discussed in more detail in the following including some of their most important battery parameters, such as charge/discharge potential and specific capacity (Figure 3 ).

\section{Conducting Polymers}

Conducting polymers, such as poly(acetylene), ${ }^{23}$ polythiophene, polypyrrole and polyaniline, were considered and tested as battery electrode materials already in the 1980s, shortly after their discovery, as discussed in more detail in several review articles. ${ }^{18,19,24}$ Most of them are p-type, but ambipolar or n-type conducting polymers also exist. Conducting polymers belong to type $\mathrm{B}$, as shown in Figure 1a; however, no defined and localized redox-active groups exist. This leads to sloping charge/ discharge curves due to a change in redox potential with increasing doping level. Furthermore, conducting polymers often showed low achievable doping levels. ${ }^{10}$ In more recent developments, higher performing conducting polymers have been reported as electrode materials, i.e. through nanostructuring. ${ }^{10,25-27}$

\section{Radical Polymers}

In the early 2000s, the so-called radical polymers, polymers containing stable radicals as side groups, were introduced. ${ }^{28-31}$ These are of type A in Figure 1a, and a variety of aliphatic polymer backbones have been employed, most frequently poly (methacrylates), poly(norbornenes), poly(acetylenes), poly (styrenes) and poly(vinylethers). ${ }^{30}$ In most cases nitroxide radicals, such as TEMPO ((2,2,6,6-tetramethylpiperidin-1-yl) oxyl), have been used. These are electrochemically ambipolar, but usually the oxidation to oxoammonium cations is more reversible than the reduction to aminoxyl anions (Figure 4a), and hence they were used as p-type materials. The most prominent example of a radical polymer is PTMA, a TEMPOradical functionalized polymethacrylate (Figure 3$)^{32}$ Its theoretical specific capacity of $111 \mathrm{mAh} \mathrm{g}^{-1}$ is nearly reached in cells, and it possesses an attractive discharge potential of $3.6 \mathrm{~V}$ versus $\mathrm{Li} / \mathrm{Li}^{+}$. Fast $\mathrm{C}$-rates are possible and high cycling stabilities have been reported due to the fast electron-transfer rate constant of the nitroxide radical. PTMA-based electrodes have been optimized with respect to many parameters and even tested in thin-film batteries ${ }^{29,33}$ as well as in pouch cells. ${ }^{34}$ Other types of nitroxide radicals have also been incorporated into polymers and used as cathode-active materials. ${ }^{28,30}$ Attaching electron-withdrawing substituents can ease the reduction, leading to n-type radical polymers. ${ }^{29,35,36}$ Employing a galvinoxyl radical as a side group also renders the polymer n-type, such as in poly(galvinoxylstyrene) (PGVS), plotted in the graph in Figure $3 .{ }^{37}$ For a more detailed overview on radical 

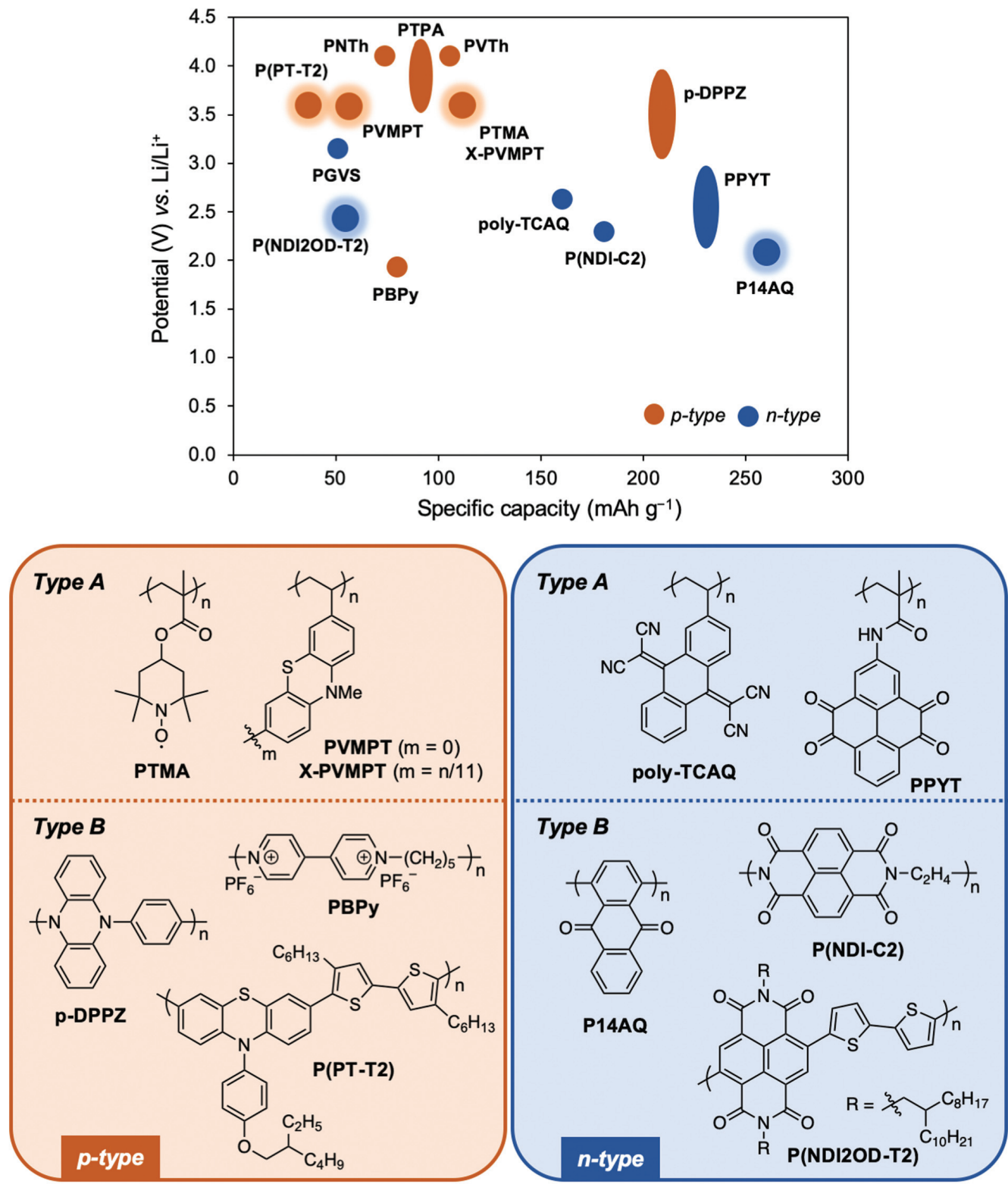

Figure 3 Charge/discharge potentials and specific capacities of selected $\mathrm{p}$ - and $\mathrm{n}$-type redox-active polymers including their structures and types [missing structures: PTPA = poly(triphenylamine), PNTh = poly(norbornylthianthrene), PVTh = poly(vinylthianthrene), PGVS = poly(galvinoxylstyrene); PBPy is shown in its oxidized form]. Particularly well-performing polymers are highlighted with a glow.

polymers as battery electrode materials, the reader is referred to several review articles. ${ }^{28-31,38-40}$

\section{Redox Polymers Incorporating Heteroaromatics}

The redox-active group can also be a closed-shell organic molecule, as long as its redox chemistry is reversible and - ideally - associated with a high electron-transfer rate constant. To date, many such examples have been reported. A few selected redox-active p-type polymers will be discussed in the following, and their redox mechanisms are shown in Figure 4b and c. Further examples can be found in several detailed review articles. ${ }^{2-4,10,41}$

Pushing the redox potential upwards increases the specific energy of the cathode, which is its product with the specific capacity. An average discharge voltage of $4.1 \mathrm{~V}$ 
(a)<smiles>[R]C1CC(C)(C)N(OC)C(C)(C)CC1(C)C=CCCC</smiles>

(b)

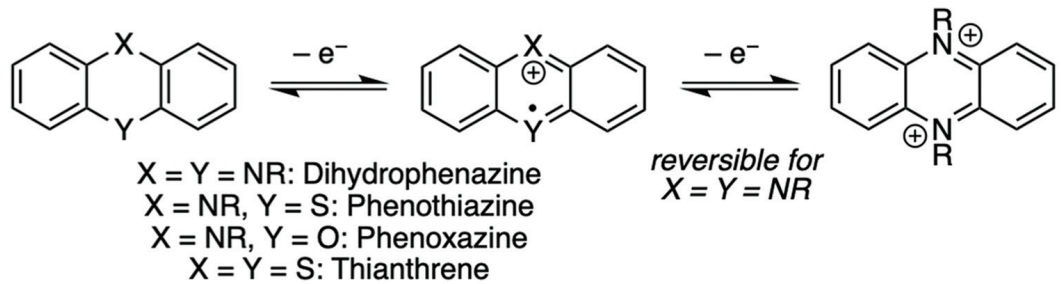

(c)

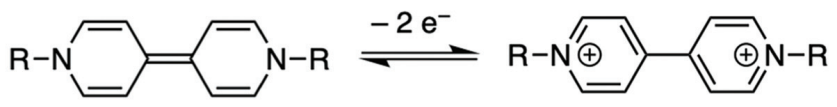

Figure 4 Redox mechanisms for selected p-type redox-active groups: (a) nitroxide radicals, (b) heteroaromatics and (c) viologens.

versus $\mathrm{Li} / \mathrm{Li}^{+}$has been demonstrated using thianthrenebased polymers as cathode-active materials. ${ }^{42,43}$ Both examples were type A polymers with a poly(norbornene) $(\mathbf{P N T h})^{42}$ or poly(vinylene) (PVTh) ${ }^{43}$ backbone (Figure 3). In the second case, an all-organic battery operating in the dualion mode was presented with PVTh as cathode-active material and a methacrylate derivative of poly-TCAQ (Figure 3) as an anode-active polymer. ${ }^{43}$

A high but more sloping discharge potential between 3.6 and $4.2 \mathrm{~V}$ versus $\mathrm{Li} / \mathrm{Li}^{+}$was obtained with a poly(triphenylamine) (PTPA, Figure 3). ${ }^{44}$ This is a type B polymer with structural and electronic similarity to conducting polymers. An impressive rate capability was demonstrated with $91 \mathrm{mAh} \mathrm{g}^{-1}$ being available at 20C-rate. The rate capability could be further improved by using a hyperbranched polymer backbone. ${ }^{45}$

A heteroaromatic with an attractively high redox potential of around $3.6 \mathrm{~V}$ versus $\mathrm{Li} / \mathrm{Li}^{+}$is phenothiazine. Several examples of phenothiazine-based redox polymers of type $A^{46-49}$ or type $B^{50-52}$ as battery cathode materials have been reported. The poly(vinylene) PVMPT (Figure 3) showed an outstanding cycling stability due to $\pi$-interactions between neighboring oxidized (and neutral) phenothiazine units. ${ }^{47,48}$ After 10,000 cycles at 10C-rate (charging/discharging in $6 \mathrm{~min}$ ), 93\% of the initial specific capacity was retained. ${ }^{47}$ This, however, came at the cost of only about half of the theoretical specific capacity being available (50 $\mathrm{mAh}^{-1}$ ). The dissolution and redisposition of PVMPT on the composite electrode upon charging and discharging facilitated the formation of $\pi$-interactions between the phenothiazine groups. ${ }^{48}$ This was circumvented by using the cross-linked variant X-PVMPT (Figure 3), which furnished a specific capacity close to the theoretical value of $112 \mathrm{mAh} \mathrm{g}^{-1} .^{49}$ This demonstrates that the insolubility of redox polymers in both their charged and discharged states needs to be considered in evaluating their battery performance. The phenoxazine-based congener PVMPO and its cross-linked derivative X-PVMPO were also recently reported with high rate performance. ${ }^{53}$

Conjugated phenothiazine copolymer P(PT-T2) of type B (Figure 3) showed an even higher cycling stability. At 100Crate (charging/discharging in 36s), P(PT-T2) provided a specific capacity of $30 \mathrm{mAh} \mathrm{g}^{-1}$ with a capacity retention of $97 \%$ after 30,000 cycles at a discharge potential of $3.6 \mathrm{~V}$ versus $\mathrm{Li} / \mathrm{Li}^{+}{ }^{52}$ The fast rates were facilitated by the semiconducting nature of the polymer backbone.

In none of the phenothiazine-based polymers discussed above, however, could the second oxidation of the phenothiazine groups to dications (occurring around $4.2 \mathrm{~V}$ vs. $\mathrm{Li} / \mathrm{Li}^{+47}$ ) be accessed in a reversible fashion.

Accessing two oxidation events becomes possible when replacing the sulfur atom by nitrogen, resulting in dihydrophenazine derivatives. Two examples of type B polymers incorporating dihydrophenazines, such as p-DPPZ, have been reported (Figure 3). ${ }^{54,55}$ Using both oxidation steps at 3.1 and $3.9 \mathrm{~V}$ versus $\mathrm{Li} / \mathrm{Li}^{+}$doubles the specific capacity of the polymers.

To build all-organic batteries that operate in the anion rocking-chair mode, p-type redox polymers with low oxidation potential are needed as anode-active materials in order to obtain a high enough cell voltage. ${ }^{5}$ This cell configuration has the advantage that it can be completely metal-free, since no metal ions from the electrolyte are needed for charge balancing. ${ }^{56}$ The only example reported so far is the viologen-based polymer PBPy with a redox 
potential of $1.9 \mathrm{~V}$ versus $\mathrm{Li} / \mathrm{Li}^{+}$(Figure 3 ), which has been tested in an all-organic anion rocking-chair battery against poly $(N$-vinylcarbazole $)$ as the cathode-active material. ${ }^{56}$ The battery operated at a potential of $1.8 \mathrm{~V}$ and delivered a specific capacity of $100 \mathrm{mAh} \mathrm{g}^{-1}$ at $1 \mathrm{C}$-rate.

\section{Carbonyl- and Bisimide-Based Redox Polymers}

Concerning n-type redox polymers, most redox-active groups are carbonyl compounds or derivatives thereof, with few exceptions. ${ }^{57}$ Several review articles solely focus on organic carbonyl compounds (redox polymers and small molecules) as battery electrode materials. ${ }^{58-61}$ The redox mechanisms of selected carbonyl-based redox-active groups are shown in Figure 5. One of the best-performing n-type redox polymers is P14AQ (Figure 3) as a type B polymer. ${ }^{62}$ At 1 C-rate, a high specific capacity of 248 mAh $\mathrm{g}^{-1}$ was accessed with $98 \%$ capacity retention after 1,000 cycles, demonstrating high cycling stability. The charge/discharge potential lies at $2.1 \mathrm{~V}$ versus $\mathrm{Li} / \mathrm{Li}^{+}$and the charge/discharge curves possess flat plateau areas, which shows that both electrons per anthraquinone unit are transferred at the same potential. ${ }^{62}$ It should be mentioned, however, that stoichiometric amounts of nickel are required for the synthesis of P14AQ through a Yamamoto coupling reaction, ${ }^{62}$ significantly increasing its environmental footprint.

For poly(bisimides), such as P(NDI-C2) with redox-active, n-type naphthalene bisimide (NDI) units (Figure 3), ${ }^{63}$ many examples have been reported. These are also type $B$ polymers, and their synthesis through polycondensation of the respective dianhydrides with diamines is extremely simple. Although theoretically a four-electron reduction (two on each imide group) should be possible, only two electrons can be transferred reversibly, providing a specific capacity of 180 $\mathrm{mAh} \mathrm{g}^{-1}$ for $\mathbf{P}(\mathbf{N D I}-\mathbf{C 2}){ }^{63}$ This happens at almost the same potential for both electrons, resulting in fairly flat charge/discharge curves with an average potential of $2.3 \mathrm{~V}$ versus $\mathrm{Li} / \mathrm{Li}^{+} .63$

High rate capability and excellent cycling stability were demonstrated using the well-known semiconducting NDIcontaining conjugated copolymer P(NDI2OD-T2) (Figure 3). ${ }^{64}$ Similar to poly(imides), P(NDI20D-T2) can be reduced by two electrons at a potential of $2.5 \mathrm{~V}$ versus $\mathrm{Li} / \mathrm{Li}^{+}$. After 3,000 cycles at $10 \mathrm{C}$-rate, $96 \%$ of the initial specific capacity of $54 \mathrm{mAh} \mathrm{g}^{-1}$ was retained, demonstrating excellent cycling stability. ${ }^{64}$ Recently P(NDI20D-T2) was also employed in a Mg-organic battery showing stable cycling with $\mathrm{MgCl}$ insertion for charge balancing. $^{65}$

As a quinone derivative, the tetracyano-9,10-anthraquinonedimethane-containing type A polymer poly-(TCAQ) (Figure 3) showed a - compared to anthraquinone - slightly

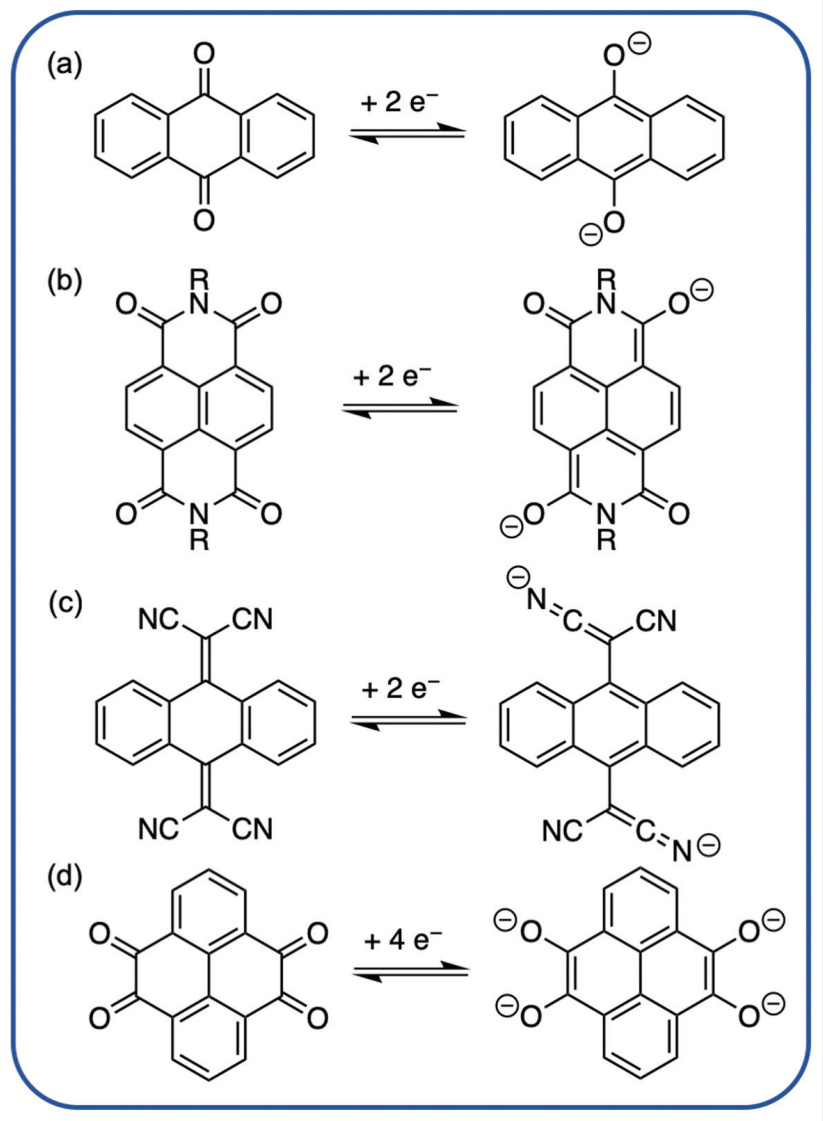

Figure 5 Redox mechanisms for selected n-type redox-active groups: (a) anthraquinone (AQ), (b) naphthalene bisimide (NDI), (c) tetracyano9,10-anthraquinonedimethane (TCAQ) and (d) pyrenetetraone (PYT).

increased charge/discharge potential of $2.7 \mathrm{~V}$ versus $\mathrm{Li} / \mathrm{Li}^{+}{ }^{66}$ A specific capacity of $156 \mathrm{mAh} \mathrm{g}^{-1}$ could be accessed with good cycling stability (88\% capacity retention after 500 cycles at 1C-rate). However, with $10 \mathrm{wt} \%$ the material loading in the composite electrode was low. A poly (methacrylate) derivative with the same redox-active group was used as an anode-active material in an all-organic battery against PVTh, as mentioned above. ${ }^{43}$

As a final example, the pyrenetetraone-containing poly (methacrylate) PPYT (Figure 3) delivered a specific capacity of $231 \mathrm{mAh} \mathrm{g}^{-1}$ in a two-step redox process with discharge potentials of 2.8 and $2.2 \mathrm{~V}$ versus $\mathrm{Li} / \mathrm{Li}^{+}$, indicating that four electrons were transferred per redox-active group. ${ }^{67}$ The cycling stability was good, the polymer retained $83 \%$ of the specific capacity after 500 cycles at 1C-rate.

\section{Conclusions and Outlook}

In summary, the examples presented above show that organic redox polymers can show high battery performance. 
Quinone- or imide-based n-type polymers can possess high specific capacities of $160-260 \mathrm{mAh} \mathrm{g}^{-1}$ with stable cycling at moderate $\mathrm{C}$-rates and discharge potentials between 2 and $2.9 \mathrm{~V}$ versus $\mathrm{Li} / \mathrm{Li}^{+}$. This makes them attractive in comparison to established transition metal-based cathodes. p-Type polymers, in comparison, provide higher discharge potentials of $3-4 \mathrm{~V}$ versus $\mathrm{Li} / \mathrm{Li}^{+}$, but usually lower specific capacities. However, as demonstrated above, superior rate capabilities and cycling stabilities at fast C-rates can be obtained with p-type radical polymers or redox polymers based on heteroaromatics. It should furthermore be mentioned that organic-based cells can show impressive temperature performance down to $-70{ }^{\circ} \mathrm{C} .68$ In all cases structural modification allows adjustment of the redox potential of the polymer. Polymer backbone engineering significantly influences battery performance, as demonstrated for P(PT-T2) and P(NDI20D-T2) with a semiconducting backbone structure or for PVMPT and X-PVMPT, where cross-linking changed the charge/discharge mechanism. Challenges in the future will be to develop novel redox-active polymers with high cycling stability, rate performance and specific capacity, to lower the amount of conductive additive required in the composite electrode in order to obtain higher specific capacities and to improve the performance of all-organic batteries.

\section{Funding Information}

Generous support by the German Research Foundation (ES 361/2-1 and ES 361/4-1), the European Union (CIG 321636), and the Chemical Industry Trust (Li 189/11) is gratefully acknowledged. Gefördert durch die Deutsche Forschungsgemeinschaft (DFG) im Rahmen der Exzellenzstrategie des Bundes und der Länder - EXC-2193/1 - 390951807. Funded by the Deutsche Forschungsgemeinschaft (DFG, German Research Foundation) under Germany's Excellence Strategy - EXC-2193/1 - 390951807.

\section{Acknowledgements}

B.E. thanks P. Acker for critical discussion of the manuscript.

\section{References}

(1) Mauger, A.; Julien, C.; Paolella, A.; Armand, M.; Zaghib, K. Materials 2019, 12, 1770.

(2) Lee, S.; Kwon, G.; Ku, K.; Yoon, K.; Jung, S-K.; Lim, H-D.; Kang, K. Adv. Mater. 2018, 30, 1704682.

(3) Schon, T. B.; McAllister, B. T.; Li, P.-F.; Seferos, D. S. Chem. Soc. Rev. 2016, 45, 6345.

(4) Song, Z.; Zhou, H. Energy Environ. Sci. 2013, 6, 2280.

(5) Poizot, P.; Dolhem, F.; Gaubicher, J. Curr. Opin. Electrochem. 2018, $9,70$.
(6) Lu, Y.; Zhang, Q.; Li, L.; Niu, Z.; Chen, J. Chem. 2018, 4, 2786.

(7) Zhang, Y.; Wang, J.; Riduan, S. N. J. Mater. Chem. A 2016, 4, 14902.

(8) Wang, S.; Li, F.; Easley, A. D.; Lutkenhaus, J. L. Nat. Mater. 2019, $18,69$.

(9) Horie, K.; Barón, M.; Fox, R. B.; He, J.; Hess, M.; Kahovec, J.; Kitayama, T.; Kubisa, E.; Maréchal, W.; Mormann, W., et al. Pure Appl. Chem. 2004, 76, 889.

(10) Muench, S.; Wild, A.; Friebe, C.; Häupler, B.; Janoschka, T.; Schubert, U. S. Chem. Rev. 2016, 116, 9438.

(11) Murray, V.; Hall, D. S.; Dahn,J. R.J. Electrochem. Soc. 2019, 166, A329.

(12) Zhao, Q.; Lu, Y.; Chen, J. Adv. Energy Mater. 2017, 7, 1601792.

(13) Zhu, Z.; Chen, J. J. Electrochem. Soc. 2015, 162, A2393.

(14) Xie, J.; Zhang, Q. Small 2019, 15, 1805061.

(15) Placke, T.; Heckmann, A.; Schmuch, R.; Meister, P.; Beltrop, K.; Winter, M. Joule 2018, 2, 2528.

(16) Wang, M.; Tang, Y. Adv. Energy Mater. 2018, 8, 1703320.

(17) Friebe, C.; Lex-Balducci, A.; Schubert, U. S. ChemSusChem 2019, 12, 4093.

(18) Novák, P.; Müller, K.; Santhanam, K. SV.; Haas, O. Chem. Rev. 1997, 97, 207.

(19) Katz, H. E.; Searson, P. C.; Poehler, T. O. J. Mater. Res. 2010, 25, 1561.

(20) Gracia, R.; Mecerreyes, D. Polym. Chem. 2013, 4, 2206.

(21) Casado, N.; Hernández, G.; Sardon, H.; Mecerreyes, D. Prog. Polym. Sci. 2016, 52, 107.

(22) Bhosale, M. E.; Chae, S.; Kim, J. M.; Choi, J-Y. J. Mater. Chem. A 2018, 6, 19885.

(23) MacInnes, D.; Druy, M. A.; Nigrey, P. J.; Nairns, D. P.; MacDiarmid, A. G.; Heeger, A. J. J. Chem. Soc. Chem. Commun. $1981,317$.

(24) Gurunathan, K.; Murugan, A. V.; Marimuthu, R.; Mulik, U.; Amalnerkar, D. Mater. Chem. Phys. 1999, 61, 173.

(25) Mike, J. F.; Lutkenhaus, J. L. J. Polym. Sci. B: Polym. Phys. 2013, 51, 468.

(26) Abdelhamid, M. E.; O’Mullane, A. P.; Snook, G. A. RSC Advances 2015, 5, 11611.

(27) Xie, J.; Gu, P.; Zhang, Q. ACS Energy Lett. 2017, 2, 1985.

(28) Nishide, H.; Koshika, K.; Oyaizu, K. Pure Appl. Chem. 2009, 81, 1961.

(29) Nakahara, K.; Oyaizu, K.; Nishide, H. Chem. Lett. 2011, 40, 222.

(30) Janoschka, T.; Hager, M. D.; Schubert, U. S. Adv. Mater. 2012, 24, 6397.

(31) Friebe, C.; Schubert, U. S. Top Curr. Chem. 2017, 375, 19.

(32) Nakahara, K.; Iwasa, S.; Satoh, M., et al. Chem. Phys. Lett. 2002, 359, 351.

(33) Suga, T.; Konishi, H.; Nishide, H. Chem. Commun. 2007, 1730.

(34) Nakahara, K.; Iriyama, J.; Iwasa, S.; Suguro, M.; Satoh, M.; Cairns, E. J. J. Power Sources 2007, 163, 1110.

(35) Suga, T.; Sugita, S.; Ohshiro, H.; Oyaizu, K.; Nishide, H. Adv. Mater. 2011, 23, 751.

(36) Suga, T.; Pu, Y.-J.; Kasatori, S.; Nishide, H. Macromolecules 2007, 40, 3167.

(37) Suga, T.; Ohshiro, H.; Sugita, S.; Oyaizu, K.; Nishide, H. Adv. Mater. 2009, 21, 1627.

(38) Oyaizu, K.; Nishide, H. Adv. Mater. 2009, 21, 2339.

(39) Tomlinson, E. P.; Hay, M. E.; Boudouris, B. W. Macromolecules 2014, 47, 6145.

(40) Nevers, D. R.; Brushett, F. R.; Wheeler, D. R. J. Power Sources 2017, 352, 226.

(41) Liang, Y.; Tao, Z.; Chen, J. Adv. Energy Mater. 2012, 2, 742.

(42) Speer, M. E.; Kolek, M.; Jassoy, J. J., et al. Chem. Commun. 2015, 51 , 15261. 
(43) Wild, A.; Strumpf, M.; Häupler, B.; Hager, M. D.; Schubert, U. S. Adv. Energy Mater. 2017, 7, 1601415.

(44) Feng, J. K.; Cao, Y. L.; Ai, X. P.; Yang, H. X. J. Power Sources 2008, 177, 199.

(45) Yamamoto, K.; Suemasa, D.; Masuda, K.; Aita, K.; Endo, T. ACS Appl. Mater. Interfaces 2018, 10, 6346.

(46) Golriz, A. A.; Suga, T.; Nishide, H.; Berger, R.; Gutmann, J. S. RSC Advances 2015, 5, 22947.

(47) Kolek, M.; Otteny, F.; Schmidt, P.; Mück-Lichtenfeld, C.; Einholz, C.; Becking, J.; Schleicher, E.; Winter, M.; Bieker, P.; Esser, B. Energy Environ. Sci. 2017, 10, 2334.

(48) Kolek, M.; Otteny, F.; Becking, J.; Winter, M.; Esser, B.; Bieker, P. Chem. Mater. 2018, 30, 6307.

(49) Otteny, F.; Kolek, M.; Becking, J.; Winter, M.; Bieker, P.; Esser, B. Adv. Energy Mater. 2018, 8, 1802151.

(50) Godet-Bar, T.; Leprêtre, J.-C.; Le Bacq, O.; Sanchez, J.-Y.; Deronzier, A.; Pasturel, A. Phys. Chem. Chem. Phys. 2015, 17, 25283.

(51) Peterson, B. M.; Ren, D.; Shen, L., et al. Energy Mater. 2018, 1, 3560.

(52) Acker, P.; Rzesny, L.; Marchiori, C. FN.; Araujo, C. M.; Esser, B. Adv. Funct. Mater. 2019, 29, 1906436.

(53) Otteny, F.; Perner, V.; Wassy, D.; Kolek, M.; Bieker, P.; Winter, M.; Esser, B. ACS Sustainable Chem. Eng. 2019, 10.1021/ acssuschemeng.9b05253.

(54) Dai, G.; Wang, X.; Qian, Y.; Niu, Z.; Zhu, X.; Ye, J.; Zhao, Y.; Zhang, X. Energy Storage Mater. 2019, 16, 236.
(55) Niu, Z.; Wu, H.; Liu, L.; Dai, G.; Xiong, S.; Zhao, Y.; Zhang, X. J. Mater. Chem. A 2019, 7, 10581.

(56) Yao, M.; Sano, H.; Ando, H.; Kiyobayashi, T. Sci. Rep. 2015, 5, 10962.

(57) Speer, M. E.; Sterzenbach, C.; Esser, B. ChemPlusChem 2017, 82, 1274.

(58) Tang, M.; Li, H.; Wang, E.; Wang, C. Chin. Chem. Lett. 2018, 29, 232.

(59) Wang, H. G.; Zhang, X. B. Chem. Eur. J. 2018, 24, 18235.

(60) Wu, Y.; Zeng, R.; Nan, J.; Shu, D.; Qiu, Y.; Chou, S-L. Adv. Energy Mater. 2017, 7, 1700278.

(61) Häupler, B.; Wild, A.; Schubert, U. S. Adv. Energy Mater. 2015, 5, 1402034.

(62) Song, Z.; Qian, Y.; Gordin, M. L.; Tang, D.; Xu, T.; Otani, M.; Zhan, H.; Zhou, H.; Wang, D. Angew. Chem. 2015, 127, 14153.

(63) Song, Z.; Zhan, H.; Zhou, Y. Angew. Chem. Int. Ed. 2010, 49, 8444.

(64) Liang, Y.; Chen, Z.; Jing, Y.; Rong, Y.; Facchetti, A.; Yao, Y. J. Am. Chem. Soc. 2015, 137, 4956.

(65) Dong, H.; Liang, Y.; Tutusaus, O.; Mohtadi, R.; Zhang, Y.; Hao, F.; Yao, Y. Joule 2018, $0,1$.

(66) Häupler, B.; Burges, R.; Janoschka, T.; Jähnert, T.; Wild, A.; Schubert, U. S. J. Mater. Chem. A 2014, 2, 8999.

(67) Nokami, T.; Matsuo, T.; Inatomi, Y.; Hojo, N.; Tsukagoshi, T.; Yoshizawa, H.; Shimizu, A.; Kuramoto, H.; Komae, K.; Tsuyama, H., et al. J. Am. Chem. Soc. 2012, 134, 19694.

(68) Dong, X.; Guo, Z.; Guo, Z.; Wang, Y.; Xia, Y. Joule 2018, 2, 902. 